\title{
Concrete contribution to initial shear strength of RC hollow bridge columns
}

\author{
Ick-Hyun Kim ${ }^{1 \mathrm{a}}$, Chang-Ho Sun ${ }^{1 \mathrm{~b}}$ and Myoungsu Shin ${ }^{2 *}$ \\ ${ }^{1}$ University of Ulsan, Department of Civil and Environmental Engineering, \\ 93 Daehak-ro, Nam-gu, Ulsan 680-749, South Korea \\ ${ }^{2}$ Ulsan National Institute of Science and Technology (UNIST), School of Urban and Environmental \\ Engineering, 100 Banyeon-ri, Eonyang-eup, Ulju-gun, Ulsan 689-798, South Korea
}

(Received April 20, 2011, Revised October 4, 2011, Accepted November 23, 2011)

\begin{abstract}
The primary objective of this study was to identify concrete contribution to the initial shear strength of reinforced concrete (RC) hollow columns under lateral loading. Seven large-scale RC rectangular hollow column specimens were tested under monotonic or cyclic lateral loads. The most important design parameter was column length-to-depth aspect ratio ranging between 1.5 and 3.0, and the other test variables included web area ratio, hollow section ratio, and loading history. The tests showed that the initial shear strength reduced in a linear pattern as the column aspect ratio increased, and one specimen tested under cyclic loading achieved approximately $83 \%$ of the shear strength of the companion specimen under monotonic loading. Also, several pioneering shear models proposed around the world, all of which were mainly based on tests for columns with solid sections, were reviewed and compared with the test results of this study, for their possible applications to columns with hollow sections. After all, an empirical equation was proposed for concrete contribution to the initial shear strength of RC hollow columns based on fundamental mechanics and the test results.
\end{abstract}

Keywords: hollow column; shear strength; aspect ratio; displacement ductility; axial load

\section{Introduction}

For reinforced concrete (RC) bridge construction, the use of hollow piers may introduce significant benefits in comparison to piers with solid sections. A hollow section with a larger depth and concentrated flanges carries a significantly larger sectional moment-of-inertia than solid sections with a similar area. The use of hollow bridge piers reduces the design seismic force owing to the smaller mass, so that it may guarantee a great savings in materials and equipment during the construction of such piers as well as their foundations, and may also reduce problems related to the hydration of massive concrete.

Unlike columns used in building frames that are typically designed following the weak beamstrong column philosophy for seismic resistance (Paulay and Priestley 1992), bridge columns are

\footnotetext{
*Corresponding author, Assistant Professor, E-mail: msshin@unist.ac.kr

${ }^{\text {a }}$ Professor

${ }^{b}$ Research Professor
} 


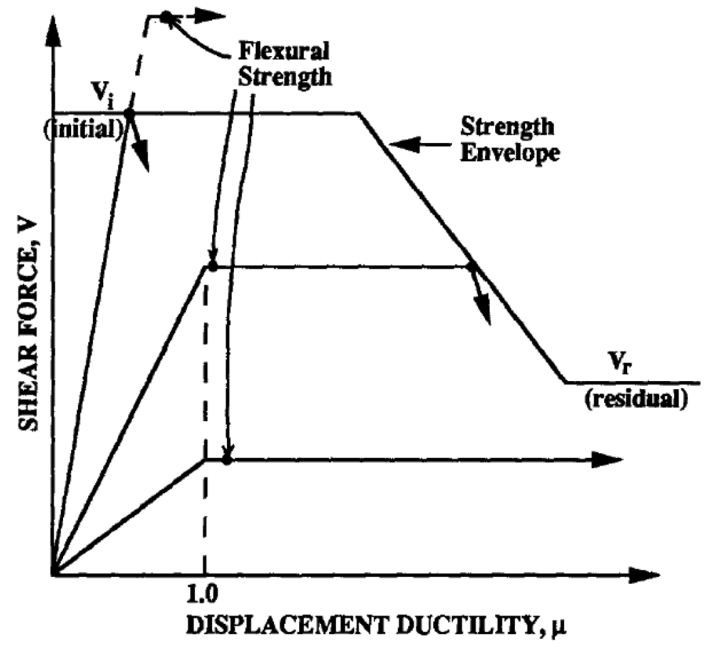

Fig. 1 ATC-6 model (1981) for relationship between shear strength and ductility

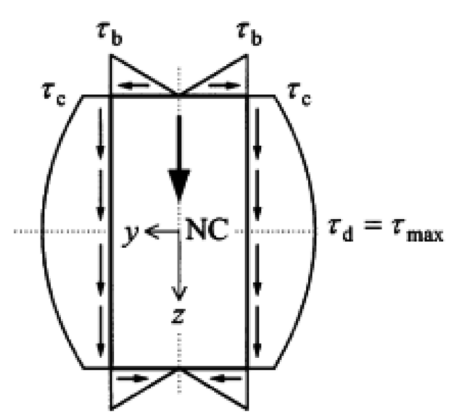

(a)

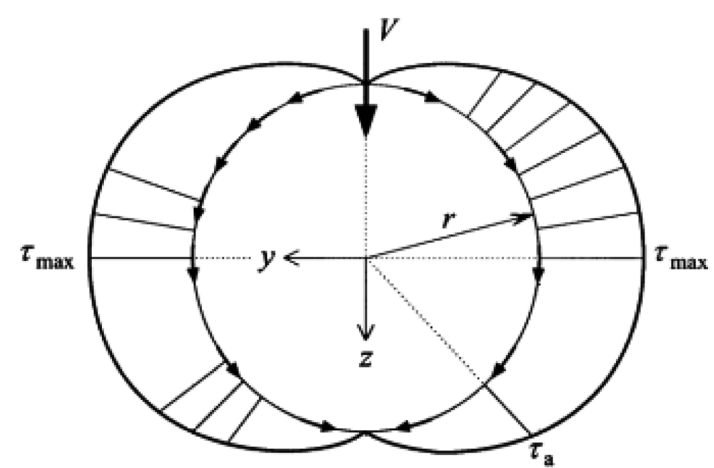

(b)

Fig. 2 Shear flow in thin-walled tube sections: (a) rectangular and (b) circular sections (adapted from Hartsuijker and Welleman 2007)

expected to have ductile flexural hinges at their bottoms under design-level earthquakes so as to function as primary sources for energy dissipation (Priestley et al. 1996). Along with the development of column hinging, brittle shear failure of bridge columns should be prevented to avoid disastrous collapse of the superstructure. Special attention should be placed on such plastic hinges, in that the shear strength of RC columns degrades when the flexural ductility demand increases (ATC-6 1981). In other words, the shear performance of RC columns strongly depends on the rate of shear strength degradation due to increasing ductility (Howser et al. 2010) as well as the initial shear strength before the degradation, $V_{i}$, as illustrated in Fig. 1.

Differences exist between the force-resisting mechanisms of solid and hollow columns subjected to lateral loading. The transmission of shear flow in hollow sections could be very similar to that in thin-walled tube sections (see Fig. 2), depending on the flange slenderness ratio. Also, the relatively 
small thickness between the inner and outer faces of a hollow section limits the available area of confined concrete core, which appears related to the shear capacity of hollow columns under cyclic loads.

Numerous studies (Ang et al. 1989, Aschheim and Moehle 1992, Wong et al. 1993, Prestley et al. 1994, Xiao and Martirossyan 1998, Kowalsky and Priestley 2000, Maekawa and An 2000, Sezen and Moehle 2004, Howser et al. 2010) proposed analytical models for evaluating the shear strength of RC columns under seismic forces. Recently, some researchers employed the Modified Compression Field Theory (MCFT) to estimate the deformation capacity of RC columns (Sezen 2008, Mostafaei et al. 2009), and others used a probabilistic approach (Sasani 2007) or a neural network based model (Yang 2007, Caglar 2009) for their shear behavior. However, all of them were primarily based on experimental tests for columns with solid sections. Only a few studies (Yeh et al. 2002, Mo et al. 2003, Mo et al. 2004, Cheng et al. 2005) have been conducted for the seismic performance assessment or the earthquake-resistant design of RC hollow columns. Moreover, little investigation was made on the initial shear strength of such columns; almost all hollow column tests reported in the literature showed relatively ductile behaviour engaging plastic hinging mechanism, before ultimate shear failure if any. Most of the studies (Mander et al. 1984, Yeh et al. 2001, Mo et al. 2003) focused on evaluating the acceptability of different lateral reinforcement details on the standpoint of sufficient ductility under cyclic lateral loading.

Given this concern, the current study investigated the initial shear strength of RC hollow bridge columns subjected to monotonic or cyclic lateral loads. In particular, this study focused on assessing concrete contribution to the column shear strength, by providing no transverse reinforcement and by imposing no axial load. It should be noted that the tests were only to investigate the initial shear strength, so that the specimens were designed to fail in shear before reaching their flexural strengths. Thus, discussions related to the effect of ductility on the column shear strength (i.e., reduction in the shear strength due to increasing ductility) are solely based on comparisons of the shear models proposed by others.

\section{Descriptions for experimental program}

\subsection{Specimen details and test variables}

Seven approximately $1 / 4$-scale rectangular hollow column specimens were tested in this study. The specimens represented cantilever bridge piers subjected to lateral loading (see Fig. 3). The single most important parameter of this experimental program was column length-to-depth aspect ratio $(l /$ $h$ ), in which $l$ stands for the column length from the base to the loading point and $h$ is the column depth. The other test variables included web area ratio, hollow section ratio, and loading pattern. The hollow section ratio was defined as the area enclosed within interior edges of a hollow section divided by the area within exterior edges of the section. Fig. 3 illustrates plan and elevation views of the test specimens, and Table 1 summarizes the design details and test variables.

In all specimens, exterior dimensions of the rectangular hollow column section were kept unchanged; $900 \mathrm{~mm}$ wide and $600 \mathrm{~mm}$ deep. Also, the specimens were reinforced with the same amount of longitudinal bars, twenty D19, in a single layer for simple construction. No transverse reinforcement was provided in all specimens to clearly identify the column shear strength exerted by concrete only. In the first four specimens (H40A1.5, H40A2.0, H40A2.5, and H40A3.0), all 


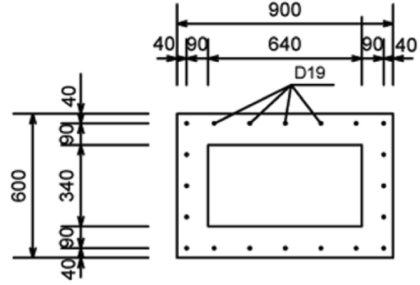

(a) H40A1.5 3.0

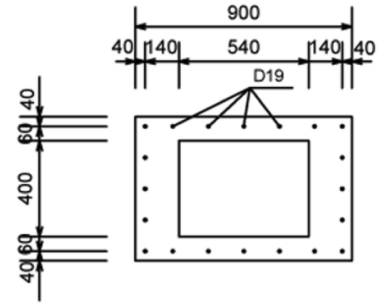

(b) H40A1.5WF1.8

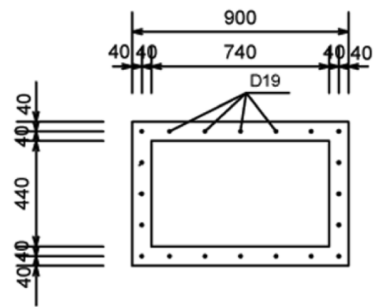

(c) H60A1.5
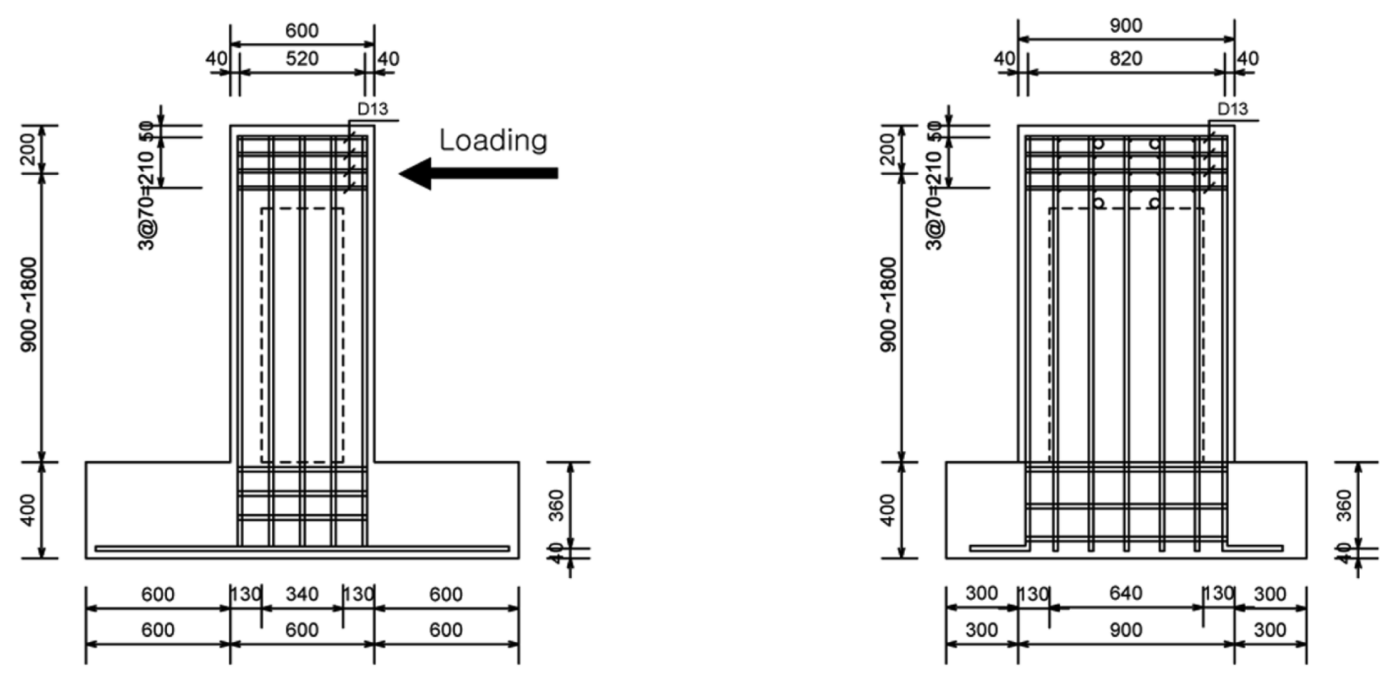

(d) Elevation views

Fig. 3 Dimensions and reinforcing details of specimens (units: $\mathrm{mm}$ )

design details were identical except the column aspect ratio $(l / h)$ varying between 1.5 and 3.0, as shown in Table 1; the web area ratio was equal to 0.48 , and the hollow section ratio was 0.4 in these specimens. Each of the two specimens, H40A1.5WF1.8 and H60A1.5, was intended for a direct comparison with $\mathrm{H} 40 \mathrm{~A} 1.5$; the former had the web area ratio of 0.67 , and the latter had the hollow section ratio of 0.6 . The specimen H40A2.0C had completely identical design details with H40A2.0, but was tested under reversed cyclic displacements.

The specimens were cast in their upright position, and all specimens were cast on the same day using an identical batch. Before casting, strain gages were installed on selected longitudinal bars at the column-footing interface. The compressive strength of concrete was $24.6 \mathrm{MPa}$, measured after 28 days since the casting, and the measured yield strength of steel for the column reinforcement was $340 \mathrm{MPa}$.

\subsection{Test setup and loading history}

Fig. 4 shows a picture of the test setup. The top of the column was linked to an actuator with a swivel connector, and the bottom was restrained by (monolithically cast with) the foundation that was anchored to the strong floor. The specimens were statically loaded in the lateral direction at the 
Table 1 Specimen details and test variables

\begin{tabular}{|c|c|c|c|c|c|c|c|}
\hline Specimen & H40A1.5 & H40A2.0 & H40A2.5 & H40A3.0 & H60A 1.5 & H40A1.5WF1.8 & $\mathrm{H} 40 \mathrm{~A} 2.0 \mathrm{C}$ \\
\hline Exterior faces (mm) & \multicolumn{7}{|c|}{$900 \times 600$} \\
\hline Interior faces (mm) & \multicolumn{4}{|c|}{$640 \times 340$} & $740 \times 440$ & $540 \times 400$ & $640 \times 340$ \\
\hline $\begin{array}{l}\text { Flange thickness } \\
(\mathrm{mm})\end{array}$ & \multicolumn{4}{|c|}{130} & 80 & 100 & 130 \\
\hline Web thickness (mm) & \multicolumn{4}{|c|}{130} & 80 & 180 & 130 \\
\hline $\begin{array}{l}\text { Gross section area, } \\
A_{g}\left(\mathrm{~mm}^{2}\right)\end{array}$ & \multicolumn{4}{|c|}{322,400} & 214,400 & 324,000 & 322,400 \\
\hline $\begin{array}{l}\text { Longitudinal } \\
\text { reinforcement ratio }\end{array}$ & \multicolumn{4}{|c|}{0.018} & 0.027 & 0.018 & 0.018 \\
\hline $\begin{array}{l}\text { Hollow section ratio } \\
(\%)\end{array}$ & \multicolumn{4}{|c|}{40} & 60 & \multicolumn{2}{|l|}{40} \\
\hline Web area ratio $(\%)$ & \multicolumn{4}{|c|}{48.4} & 44.8 & 66.7 & 48.4 \\
\hline $\begin{array}{l}\text { Column length, } l \\
(\mathrm{~mm})\end{array}$ & 900 & 1200 & 1500 & 1800 & 900 & 900 & 1200 \\
\hline Aspect ratio, $l / h$ & 1.5 & 2.0 & 2.5 & 3.0 & 1.5 & 1.5 & 2.0 \\
\hline Loading pattern & \multicolumn{6}{|c|}{ Monotonic loading } & $\begin{array}{l}\text { Cyclic } \\
\text { loading }\end{array}$ \\
\hline Material strengths & \multicolumn{7}{|c|}{ Concrete compressive strength: $24.6 \mathrm{MPa}$, Steel yield strength: $340 \mathrm{MPa}$} \\
\hline Main test variables & \multicolumn{4}{|c|}{ Aspect ratio } & $\begin{array}{l}\text { Hollow } \\
\text { section } \\
\text { ratio }\end{array}$ & Web area ratio & $\begin{array}{l}\text { Loading } \\
\text { pattern }\end{array}$ \\
\hline
\end{tabular}

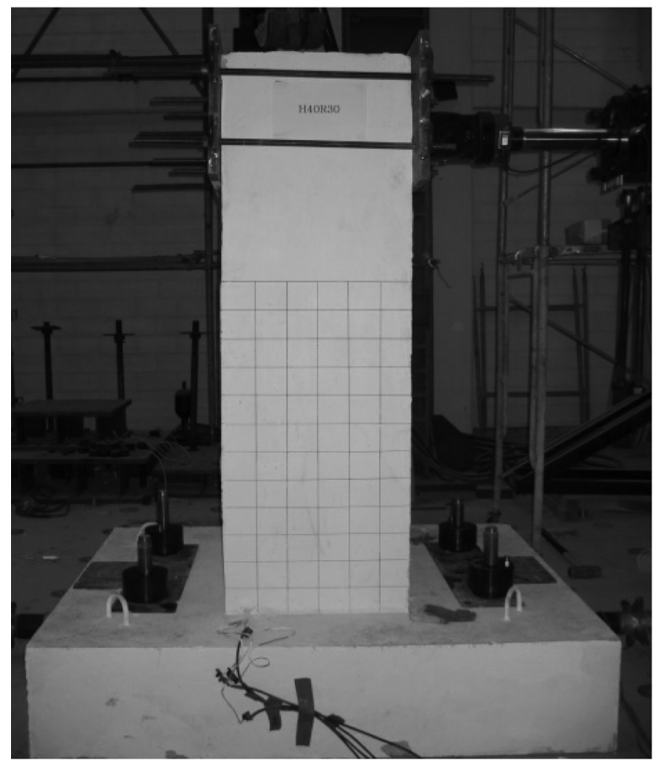

Fig. 4 A picture of the test setup 


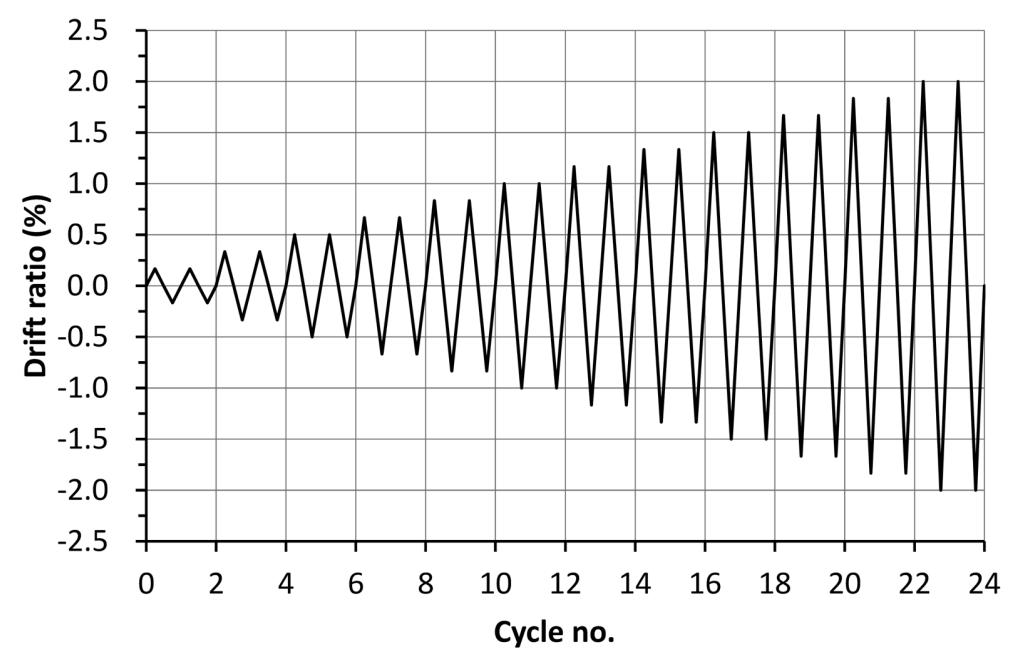

Fig. 5 Loading history for specimen H40A2.0C
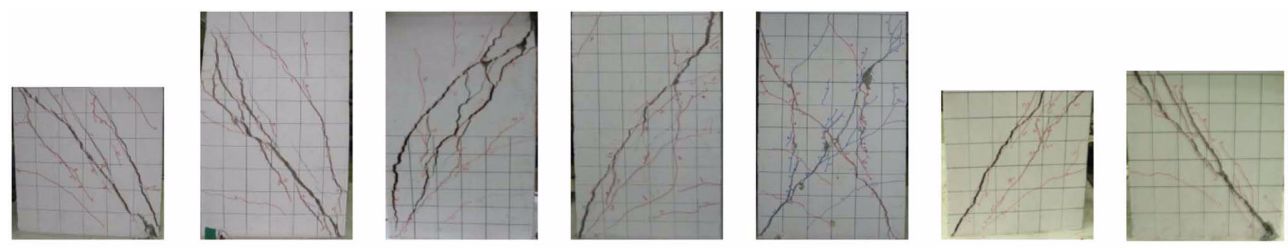

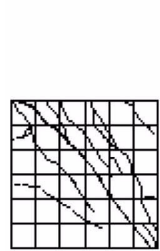

(a)

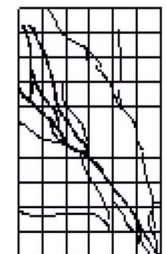

(b)

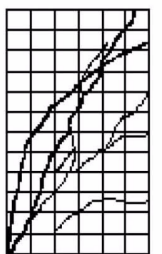

(c)

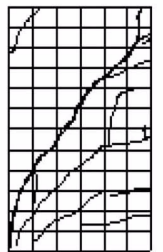

(d)

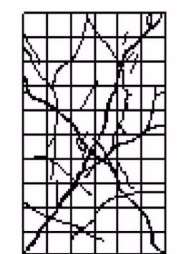

(e)

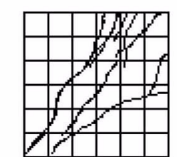

(f)

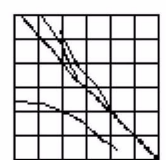

(g)

H40A1.5 H40A2.0

H40A3.0

$\mathrm{H} 40 \mathrm{~A} 2.0 \mathrm{C}$

H40A1.5

H60A1.5

WF1.8

Fig. 6 Cracking damage at completion of testing

top of the column, by a hydraulic actuator with a $500 \mathrm{kN}$ loading capacity and a $\pm 300 \mathrm{~mm}$ linear stroke. No column axial load was applied to exclude any potential contribution of axial load to the column shear strength.

Each specimen except H40A2.0C was tested under monotonic loading until it failed in shear to show a significant strength drop larger than $20 \%$ from the maximum load. For H40A2.0C, a total of twenty-four displacement cycles were statically applied up to $2 \%$ drift ratio as shown in Fig. 5. Two consecutive same-drift cycles were tested to examine strength and stiffness degradations under repeated loading. 


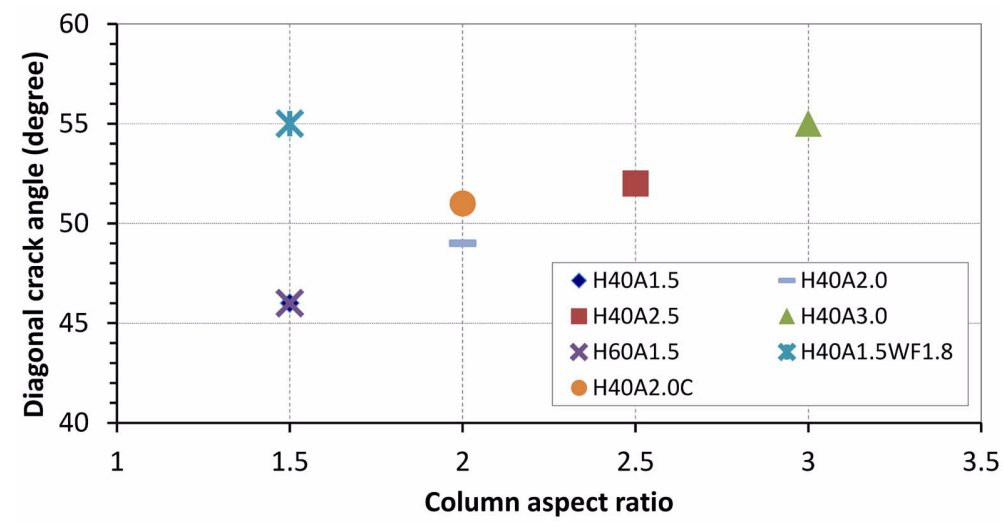

Fig. 7 Angle of diagonal cracks with respect to column aspect ratio

\section{Summary of test results}

\subsection{Cracking behavior and failure mode}

Fig. 6 illustrates cracking damages observed in the specimens at the completion of testing. In all specimens, initial inclined cracks occurred at approximately 0.4 to $0.6 \%$ drift ratio, connecting to one corner (on the opposite side of the actuator pushing the specimen) of the column base. It is notable that the drift ratio at the onset of inclined cracks was similar in the specimens regardless of the varying test parameters. The crack width gradually increased to result in a couple of major inclined cracks until the specimen failed with a significant strength drop of more than $20 \%$ of the peak load. Fig. 6 shows only one side of each specimen that had more apparent inclined cracks. In all specimens, no indication or behavior related to typical flexural failure was found such as concrete spalling or reinforcement buckling near the bottom of the column; only a couple of hairline horizontal cracks were observed in the specimens with the column aspect ratio equal to or larger than 2. Based on these and other observations discussed later, it was concluded that all specimens failed in shear.

The angles of the major inclined cracks measured from the horizontal line ranged approximately between 45 and 55 degrees, as shown in Fig. 7. In general, the specimen with the higher aspect ratio showed the greater crack angle. Also, the specimen with the higher web area ratio exhibited the greater crack angle (compare H40A1.5 vs. H40A1.5WF1.8), while the specimen with the higher hollow section ratio had similar cracks (compare H40A1.5 vs. H60A1.5).

\subsection{Overall load-displacement response}

Fig. 8 illustrates the lateral load vs. drift responses of all seven specimens. The drift ratio was defined as the displacement at the loading level divided by the column length $(l)$, measured from the column base to the loading point. The initiation of inclined cracking indicated in Fig. 8 was determined by visual observation and the onset of first yielding was by strain gage data. The lateral stiffness of the specimen became smaller as the specimen underwent more cracking damage and/or reinforcement yielding. In all tests, the lateral strength of the specimen was limited by shear failure, 


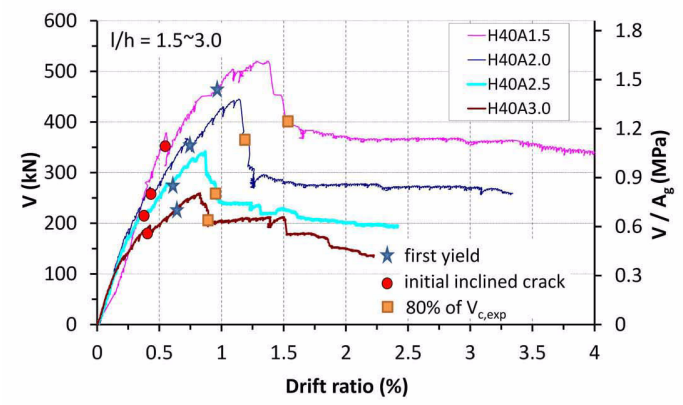

(a) $\mathrm{H} 40 \mathrm{~A} 1.5, \mathrm{H} 40 \mathrm{~A} 2.0, \mathrm{H} 40 \mathrm{~A} 2.5 \& \mathrm{H} 40 \mathrm{~A} 3.0$

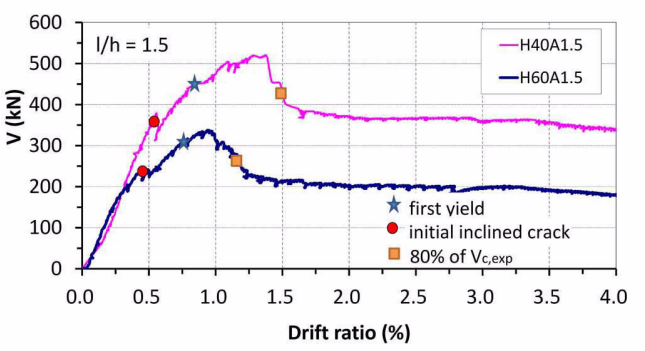

(c) H40A1.5 vs. H60A1.5 (in force term)

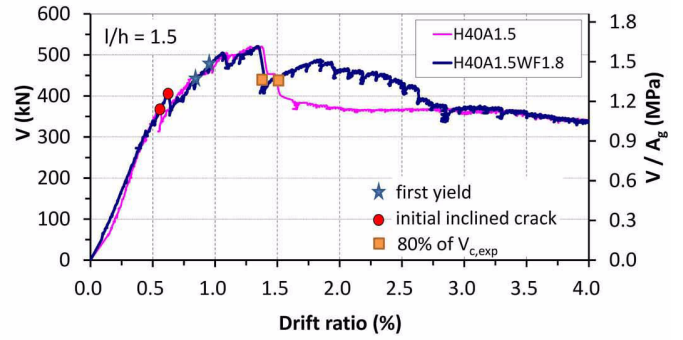

(b) H40A1.5 vs. H40A 1.5 WF1.8

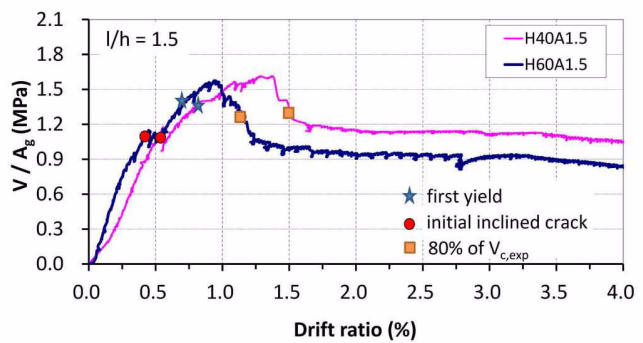

(d) H40A1.5 vs. H60A1.5 (in stress term)

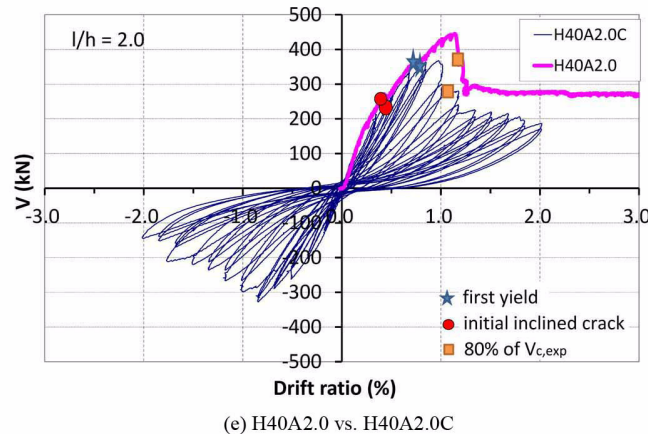

Fig. 8 Load-displacement responses of specimens

and suddenly dropped by more than $20 \%$ of the maximum load achieved at between 0.8 and $1.4 \%$ drift ratio. Table 2 summarizes the maximum load $\left(V_{c, \text { exp }}\right)$ reached during each test, which was considered as the shear strength of the column because all seven specimens failed ultimately due to shear. The shear strength normalized by the gross section area $\left(A_{g}\right)$ or the web area $\left(b_{w} d\right)$ was listed together in Table 2. Also, the possible lateral strength of each specimen $\left(V_{c, f l e x}\right)$ was calculated assuming that a plastic hinge due to flexure would develop at the bottom of the column, as well as the lateral load when the calculated yield moment occurred at the base $\left(V_{c \text {, vield }}\right)$ (see the first and second rows of Table 2). In all specimens, the measured maximum load $\left(V_{c, \text { exp }}\right)$ during the test was smaller than the calculated lateral strength $\left(V_{c, \text { flex }}\right)$ based on the flexural hinging mechanism; most specimens experienced limited yielding. This was in accordance with the conclusion that all specimens failed due to shear with very low ductility. 
Table 2 Measured and calculated lateral strengths and failure modes of specimens

\begin{tabular}{|c|c|c|c|c|c|c|c|}
\hline Specimen & H40A1.5 & H40A2.0 & $\mathrm{H} 40 \mathrm{~A} 2.5$ & H40A3.0 & H60A1.5 & H40A1.5WF1.8 & $\mathrm{H} 40 \mathrm{~A} 2.0 \mathrm{C}$ \\
\hline $\begin{array}{l}\text { Flexural strength, } \\
V_{c, \text { flex }}(\mathrm{kN})\end{array}$ & 620 & 464 & 371 & 310 & 619 & 616 & 471 \\
\hline $\begin{array}{l}\text { Yield strength, } \\
V_{c, \text { yield }}(\mathrm{kN})\end{array}$ & 471 & 338 & 268 & 224 & 474 & 463 & 338 \\
\hline $\begin{array}{l}\text { Maximum load, } \\
V_{c, \exp }(\mathrm{kN})\end{array}$ & 525 & 445 & 341 & 259 & 337 & 522 & 368 \\
\hline $\begin{array}{l}V_{c, \exp } / A_{g} \\
(\mathrm{MPa})\end{array}$ & 1.63 & 1.38 & 1.06 & 0.80 & 1.57 & 1.62 & 1.14 \\
\hline $\begin{array}{l}V_{c, \exp } / b_{w} d \\
(\mathrm{MPa})\end{array}$ & 3.37 & 3.05 & 2.34 & 1.78 & 3.76 & 3.33 & 2.53 \\
\hline $\begin{array}{l}V_{c, \exp } / A_{e}{ }^{*} \\
(\mathrm{MPa})\end{array}$ & 2.02 & 1.73 & 1.32 & 1.00 & 1.96 & 2.02 & 1.43 \\
\hline Failure mode & $\begin{array}{l}\text { Flexure- } \\
\text { shear }\end{array}$ & $\begin{array}{l}\text { Flexure- } \\
\text { shear }\end{array}$ & $\begin{array}{l}\text { Flexure- } \\
\text { shear }\end{array}$ & $\begin{array}{l}\text { Flexure- } \\
\text { shear }\end{array}$ & Shear & Flexure-shear & Flexure-shear \\
\hline
\end{tabular}

* $A_{e}$ : Effective area equal to $0.8 A_{g}$

Effects of the main test variables on the lateral load-drift response were analyzed in the following. Comparing the four specimens (H40A1.5, H40A2.0, H40A2.5, and H40A3.0) with the column aspect ratio $(l / h)$ varied only, the specimen with the higher aspect ratio exhibited the smaller stiffness after initial inclined cracks appeared, and ultimately reached the smaller maximum load $\left(V_{c, \exp }\right)$ at the smaller drift ratio (see Fig. 8(a)). The reduction in the shear strength $\left(V_{c, \exp }\right)$ was likely in part because the confinement effect of the adjacent member (i.e., footing) was lesser in columns with higher aspect ratios (Kowalsky and Priestley 2000), and also in part because increased normal stress due to higher bending moment interacted with shear stress against the given tensile capacity of concrete.

The two specimens, H40A1.5 and H40A1.5WF1.8, with different web area ratios (approximately 0.48 and 0.67 respectively) but with the same gross section area $\left(A_{g}\right)$, achieved similar maximum loads $\left(V_{c, \text { exp }}\right)$ in the tests. Also, the measured shear strength $\left(V_{c, \text { exp }}\right)$ divided by the gross section area $\left(A_{g}\right)$ was 1.63 and $1.62 \mathrm{MPa}$ in H40A1.5 and H40A1.5WF1.8 respectively, which were reasonably close to the values estimated by some shear models proposed earlier (see Tables 2 and 4). Based on these results, the initial shear strength of a hollow column appears to be associated more with the gross section $\left(A_{g}\right)$ than the web area $\left(b_{w} d\right)$.

Figs. 8(c) and 8(d) compare the lateral load-drift responses of H40A1.5 and H60A1.5, with the hollow section ratio equal to 0.4 and 0.6 , respectively. H40A1.5 (with the larger section area) certainly had the greater maximum load $\left(V_{c, \text { exp }}\right)$ at about $1.4 \%$ drift ratio, which was quite larger than $0.9 \%$ in H60A1.5. However, $V_{c, \text { exp }}$ normalized by $A_{g}$ was similar to be 1.63 and $1.57 \mathrm{MPa}$ in H40A1.5 and H60A1.5 respectively (see Table 2), regardless of the hollow section ratio. This supported the conclusion that the initial shear strength of a hollow column would be dependent more on $A_{g}$ than $b_{w} d$. On the other hand, the percentage of strength drop after the maximum load was lesser in H40A1.5. This was possibly because aggregate interlocking across inclined cracks was less effective in H60A1.5 because of the smaller web thickness. However, more tests should be 


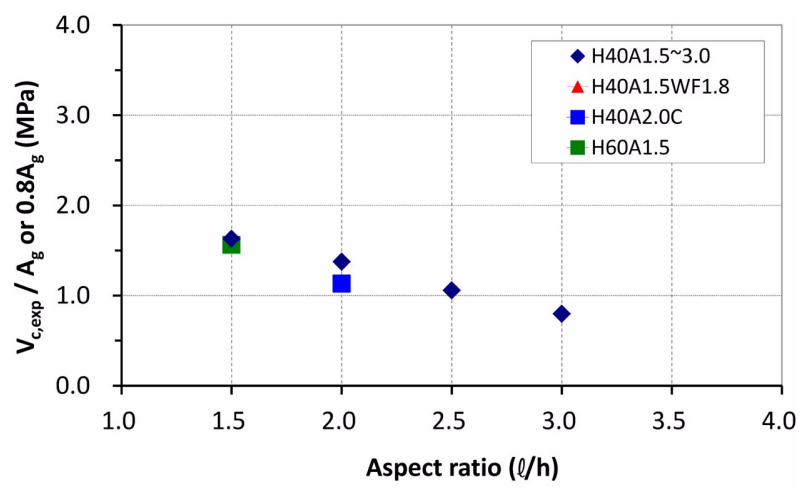

Fig. 9 Experimental shear strength divided by $A_{g}$ or $0.8 A_{g}$

done to reach a certain conclusion on the level of the residual strength.

In this experimental program, one specimen, $\mathrm{H} 40 \mathrm{~A} 2.0 \mathrm{C}$, was tested under reversed cyclic loading to investigate effects of different loading histories. Fig. 8(e) compares the load-drift responses of H40A2.0 and H40A2.0C, in which design details were exactly identical. H40A2.0C achieved the smaller maximum load (roughly $83 \%$ of that of H40A2.0) at the smaller drift ratio. This was mostly because H40A2.0C underwent strength and stiffness degradations due to continued increase of the principal tensile strain after the onset of reinforcement yielding (Stevens et al. 1991).

Fig. 9 illustrates the measured shear strength $\left(V_{c, \text { exp }}\right)$ normalized by the gross section area $\left(A_{g}\right)$ or the effective area ( $0.8 A_{g}$ for $\mathrm{H} 40 \mathrm{~A} 2.0 \mathrm{C}$ only), with respect to the column aspect ratio $(l / h)$. The normalized shear strength $\left(V_{c, \text { exp }} / A_{g}\right.$ or $\left.V_{c, \text { exp }} / 0.8 A_{g}\right)$ decreased generally in a linear proportion to the aspect ratio. Note that, in all specimens except $\mathrm{H} 40 \mathrm{~A} 2.0 \mathrm{C}$, the gross section area, $A_{g}$, was used, while $0.8 A_{g}$ was used as the effective area for H40A2.0C. The two different shear areas $\left(A_{g}\right.$ versus $\left.0.8 A_{g}\right)$ were adopted based on the findings that the shear strength of $\mathrm{H} 40 \mathrm{~A} 2.0 \mathrm{C}$ was roughly $83 \%$ of that of $\mathrm{H} 40 \mathrm{~A} 2.0$.

\section{Comparison of shear models with test results}

Many researchers have focused on the evaluation of the shear strength of RC columns all around the world, most of which were mainly based on tests of columns with solid sections. Some of the pioneering studies on this subject were reviewed and compared with the test results, for their possible applications to columns with hollow sections. The studies reviewed in this paper include Aschheim and Moehle (1992), Prestley et al. (1994), Xiao and Martirossyan (1998), Kowalsky and Priestley (2000), Maekawa and An (2000), Sezen and Moehle (2004), and Howser et al. (2010). Also, two relevant design codes, ACI 318-08 (2008) for the design of new buildings and Caltrans Seismic Design Criteria (2002) for the assessment and design of bridges, were investigated, while other earlier design approaches such as in ATC-32 (1996), ATC-40 (1996), FEMA 273 (1997), FEMA 356 (2000), and ASCE/SEI 41-06 (2006) essentially adopted the aforesaid methods. Important design parameters that have been considered to affect concrete contribution to the column shear strength in the previous studies and design codes are column aspect ratio $(l / h)$, displacement ductility $(\mu)$, axial load $(P)$, longitudinal reinforcement ratio $\left(\rho_{l}\right)$, size effect, and the effective area resistant to shear. All equations introduced in the following are written in SI units. 


\subsection{Aschheim and Moehle (1992)}

Aschheim and Moehle (1992) proposed that concrete contribution to the shear strength of an RC column degrades when displacement ductility demand increases. In this model, the concrete contribution $\left(V_{c}\right)$ is determined by

$$
\begin{gathered}
V_{c}=0.3\left(k+\frac{P}{13.8 A_{g}}\right) \sqrt{f_{c}^{\prime}}\left(0.8 A_{g}\right) \\
k=\frac{4-\mu}{3} ; \quad 0 \leq k \leq 1
\end{gathered}
$$

Here, $k$ is the factor accounting for the aforesaid effect of increasing displacement ductility $(\mu)$. This model was intended to evaluate the shear strength at plastic hinge zones, and was later adopted in FEMA 273 (1997).

\subsection{Original UCSD shear model}

According to Priestley et al. (1994), the shear strength of RC columns is attributed to the following three parts: contributions by concrete, transverse reinforcement, and compressive load. They suggested that the concrete shear strength $\left(V_{c}\right)$ degrades with increasing ductility as follows:

$$
V_{c}=\gamma \sqrt{f_{c}^{\prime}}\left(0.8 A_{g}\right)
$$

Here, the $\gamma$ factor is taken as 0.29 when the displacement ductility $(\mu)$ is less than 2 and 0.10 when $\mu$ is more than 4 . The $\gamma$ factor linearly decreases between $\mu$ equal to 2 and 4 . They noted that the strength degradation is primarily because aggregate interlocking reduces as cracks become wider. Another unique feature of the original UCSD model was that the contribution of axial load on the column shear strength was separated from the concrete contribution.

A few years later, Xiao and Martirossyan (1998) investigated the seismic performance of highstrength concrete columns, and found that concrete shear contribution in such columns degraded more dramatically than that predicted by the original UCSD model (1994). Based on the test results, they proposed to modify the $\gamma$ factor for the case of high-strength concrete as follows:

$$
\begin{gathered}
\gamma=0.29 \quad \text { for } \mu \leq 2 \\
\gamma=0.29-0.12(\mu-2) \quad \text { for } 2 \leq \mu \leq 4 \\
\gamma=0.05-0.025(\mu-4) \quad \text { for } 4 \leq \mu \leq 6 \\
\gamma=0 \quad \text { for } \mu \geq 6
\end{gathered}
$$

In this model, the initial concrete contribution (for $\mu$ close to 1 ) is identical (i.e., $\gamma=0.29$ ) to that of the original UCSD model. They noted, however, that the proposed equation was not calibrated for high-strength concrete columns that underwent shear failure with $\mu$ less than 4 . 
Recently, Howser et al. (2010) also proposed modifications to the $\gamma$ factor in the original UCSD model (i.e., the effect of ductility on the concrete shear strength), based on a numerical parametric study:

$$
\begin{gathered}
\gamma=0.29 \quad \text { for } \mu \leq 2 \\
\gamma=0.29-0.12(\mu-2) \quad \text { for } 2 \leq \mu \leq r \\
\gamma=0.53-0.095 r-0.025 \mu \quad \text { for } r \leq \mu \leq q \\
\gamma=0.53-0.095 r-0.025 q \quad \text { for } \mu \geq q \\
r=35 \rho_{t}-0.011 f_{c}^{\prime}+3.8 \\
q=-144 \rho_{t}+0.03 f_{c}^{\prime}+4.3 \quad \text { for } q \geq r \\
q=r \quad \text { for } q<r
\end{gathered}
$$

As implied above, the numerical results well agreed with Xiao and Martirossyan (1998) for small ductilities, while adjustments were made in this model for large ductilities.

\subsection{Revised UCSD shear model}

Kowalsky and Priestley (2000) proposed three revisions to the earlier UCSD shear model of Priestley et al. (1994). The revisions account for (1) the effect of column aspect ratio and (2) the effect of longitudinal steel ratio on the concrete shear-resisting mechanism. The concrete contribution $\left(V_{c}\right)$ to the shear strength of RC columns is defined as

$$
\begin{gathered}
V_{c}=\alpha \beta \gamma \sqrt{f_{c}^{\prime}}\left(0.8 A_{g}\right) \\
\alpha=3-\frac{M}{V D} ; \quad 1 \leq \alpha \leq 1.5 \\
\beta=0.5+20 \rho_{l} \leq 1 \\
\gamma=0.29-0.04(\mu-2) ; \quad 0.05 \leq \gamma \leq 0.29
\end{gathered}
$$

Here, the $\alpha$ factor accounts for the impact of column aspect ratio represented by $M / V D$, where $D$ is the diameter of a circular column. They noted that shorter columns would have better confinement by the adjacent joints or footings. The $\beta$ factor is linearly proportional to the longitudinal steel ratio $\left(\rho_{1}\right)$ that would affect aggregate interlocking mechanism across concrete cracks, and the $\gamma$ factor stands for the degradation of concrete shear capacity with increasing displacement ductility $(\mu)$.

\subsection{Maekawa and An (2000)}

Maekawa and An (2000) introduced a modification factor for the current JSCE (Japanese Society 
of Civil Engineers) formula for the shear strength carried by concrete $\left(v_{c, J S C E}\right)$, to account for the post-yield shear capacity of RC columns. This model integrates combined effects of column aspect ratio and displacement ductility as follows:

$$
\begin{gathered}
V_{c}=(1-k(\mu-1)) v_{c, J S C E}\left(b_{w} d\right) \\
k=\frac{1}{2(9-a / d)} \\
v_{c, J S C E}=0.9\left(f_{c}^{\prime}\right)^{1 / 3} \cdot \beta_{p} \cdot \beta_{n} \cdot \beta_{d}\left(\frac{a}{d} \geq 2.0\right) \\
v_{c, J S C E}=0.6\left(f_{c}^{\prime}\right)^{1 / 2} \cdot \beta_{p} \cdot \beta_{n} \cdot \beta_{d}\left(\frac{a}{d}<2.0\right)
\end{gathered}
$$

Here, the modification factor expressed as $1-k(\mu-1)$ is limited to 1 when $\mu<1$ and is taken as 0 when $\mu>1+1 / k$, where $k$ is a factor accounting for the effect of column aspect ratio $(a / d)$. It is noted that the effect of aspect ratio is also considered in $v_{c, J S C E}$.

\subsection{Sezen and Moehle (2004)}

Sezen and Moehle (2004) developed a comprehensive shear model for older columns having less transverse reinforcement, compared with columns designed following current codes. In this model, the concrete contribution $\left(V_{c}\right)$ is affected by column aspect ratio $(a / d)$, displacement ductility $(\mu)$, and axial load $(P)$, and varies in proportion to the inverse of the aspect ratio, as recommended in the ASCE-ACI Committee 426 report (1973):

$$
\begin{gathered}
V_{c}=k\left(\frac{0.5 \sqrt{f_{c}^{\prime}}}{a / d} \sqrt{1+\frac{P}{0.5 \sqrt{f_{c}^{\prime}} A_{g}}}\right) 0.8 A_{g} \\
k=1 \text { when } \mu \leq 2, k=0.7 \text { when } \mu \geq 6
\end{gathered}
$$

Here, the $k$ factor decreases linearly from 1 to 0.7 for $\mu$ varying between 2 and 6 . Unlike in any other models, the $k$ factor is also multiplied to reinforcement contribution to the shear strength of $\mathrm{RC}$ columns, in that concrete damage likely leads to loss of anchorage of longitudinal and transverse reinforcement so as to degrade the truss mechanism (Sezen and Moehle 2004). This method was adopted in ASCE/SEI 41-06 (2006), the most recent report for the subject of the "seismic rehabilitation of existing buildings," which succeeded the previous editions on the same subject, FEMA 273 (1997) and FEMA 356 (2000).

\subsection{Caltrans seismic design criteria}

Unlike other design codes such as ACI 318-08 (2008) and AASHTO Specifications (2002), Caltrans Seismic Design Criteria (2002) introduced the effect of increasing displacement ductility 
$(\mu)$ in determining concrete contribution $\left(V_{c}\right)$ to the shear strength of RC columns:

$$
\begin{gathered}
V_{c}=F_{1} F_{2} \sqrt{f_{c}^{\prime}}\left(0.8 A_{g}\right) \leq 0.33 \sqrt{f_{c}^{\prime}} A_{g} \\
F_{1}=0.08 \rho_{s} f_{y h}+0.305-0.083 \mu ; \quad 0.025 \leq F_{1} \leq 0.25 \\
F_{2}=1+\frac{P}{13.8 A_{g}} ; \quad 1 \leq F_{2} \leq 1.5
\end{gathered}
$$

Here, $\rho_{\mathrm{s}}$ is the transverse reinforcement ratio and $f_{y h}$ is the yield strength of transverse steel. The correction factor for the level of axial load, $F_{2}$, is the same as that of ACI 318-08, $\S 11.3$ applying to columns not designed to resist seismic forces.

\subsection{ACl 318-08 shear strength equation}

For the design of new buildings based on ACI 318-08, the concrete contribution $\left(V_{c}\right)$ is determined considering column aspect ratio, longitudinal reinforcement ratio, and axial load by

$$
\begin{gathered}
V_{c}=\left(0.16 \sqrt{f_{c}^{\prime}}+17 \rho_{w} \frac{V_{u} d}{M_{m}}\right) b_{w} d \\
M_{m}=M_{u}-N_{u} \frac{(4 h-d)}{8}
\end{gathered}
$$

Here, $\rho_{w}$ is the longitudinal reinforcement area divided by $b_{w} d, N_{u}$ is the ultimate axial load, $V_{u}$ is the ultimate shear force, $M_{u}$ is the ultimate moment, $d$ is the effective depth of the section, and $h$ is the total depth of the section. The beneficial effect of compressive axial load is indirectly reflected in Eq. (22), and the maximum moment demand, $M_{m}$, is used instead of $M_{u}$ in Eq. (21) to modify the effect of column aspect ratio, which is represented by $M_{m} / V_{u} d$.

\subsection{Comparison of various shear models}

The shear models reviewed above were compared each other in terms of several major design parameters, as summarized in Table 3. All models except for ACI 318-08 take into account the effect of displacement ductility on the shear strength of RC columns. Also, reduction in the concrete shear contribution due to the larger column aspect ratio is reflected in many models including the revised UCSD model, Maekawa and An (2000), Sezen and Moehle (2004), and ACI 318-08. With respect to the effective area resistant to shear, Maekawa and An (2000) and ACI 318-08 use the web area $\left(b_{w} d\right)$ of the column section, while all other models use $80 \%$ of the gross section area $\left(A_{g}\right)$ to account for reduction in the shear effective area due to cracking and spalling damage near plastic zones under reversed cyclic loading (Ang et al. 1989).

Fig. 10(a) compares the various shear models in terms of the impact of displacement ductility demand for cases of the column aspect ratio equal to 2 as an example. In Figs. 10 and 11, the longitudinal steel ratio is taken as that of the specimens in this study, and both the transverse steel ratio and the axial load are taken as zero, in order to compare the concrete contribution only. With regard to the effect of ductility demand, shear strength degradation initiates at the displacement ductility of 1 in Aschheim and Moehle (1992) and Maekawa and An (2000), and at 2 in all the 
Table 3 Design parameters considered in various shear models

\begin{tabular}{|c|c|c|c|c|c|c|c|}
\hline Shear model & Section type & Ductility & $\begin{array}{l}\text { Aspect } \\
\text { ratio }\end{array}$ & $\begin{array}{l}\text { Long. steel } \\
\text { ratio }\end{array}$ & Axial load & Shear area & Remarks \\
\hline $\begin{array}{l}\text { Aschheim \& Moehle } \\
\text { (1992) }\end{array}$ & Circular & $\bigcirc$ & $x$ & $\times$ & $\bigcirc$ & $0.8 \mathrm{Ag}$ & - \\
\hline $\begin{array}{l}\text { Priestley et al. } \\
\text { (1994) }\end{array}$ & $\begin{array}{l}\text { Circular } \\
\text { Rectangular }\end{array}$ & $\bigcirc$ & $\times$ & $\times$ & $\times$ & $0.8 \mathrm{Ag}$ & - \\
\hline $\begin{array}{l}\text { Xiao \& } \\
\text { Martirossyan (1998) }\end{array}$ & Rectangular & $\bigcirc$ & $\times$ & $\times$ & $\times$ & $0.8 \mathrm{Ag}$ & - \\
\hline $\begin{array}{l}\text { Priestley \& } \\
\text { Kowalsky (2000) }\end{array}$ & Circular & $\bigcirc$ & $\bigcirc$ & $\bigcirc$ & $x$ & $0.8 \mathrm{Ag}$ & - \\
\hline $\begin{array}{l}\text { Maekawa \& An } \\
(2000)\end{array}$ & Rectangular & $\bigcirc$ & $\bigcirc$ & $\times$ & $\times$ & $b_{w} d$ & Size effect \\
\hline Caltrans (2002) & - & $\bigcirc$ & $\times$ & $x$ & $\bigcirc$ & $0.8 \mathrm{Ag}$ & $\begin{array}{l}\text { Lateral steel } \\
\text { ratio }\end{array}$ \\
\hline $\begin{array}{l}\text { Sezen \& Moehle } \\
\text { (2004) }\end{array}$ & Rectangular & $\bigcirc$ & $\bigcirc$ & $x$ & $\bigcirc$ & $0.8 \mathrm{Ag}$ & - \\
\hline ACI 318-08 (2008) & - & $\times$ & $\bigcirc$ & 0 & 0 & $b_{w} d$ & - \\
\hline
\end{tabular}

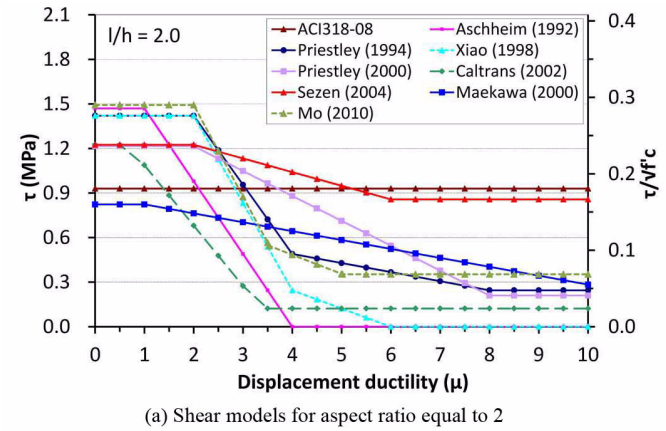

(a) Shear models for aspect ratio equal to 2

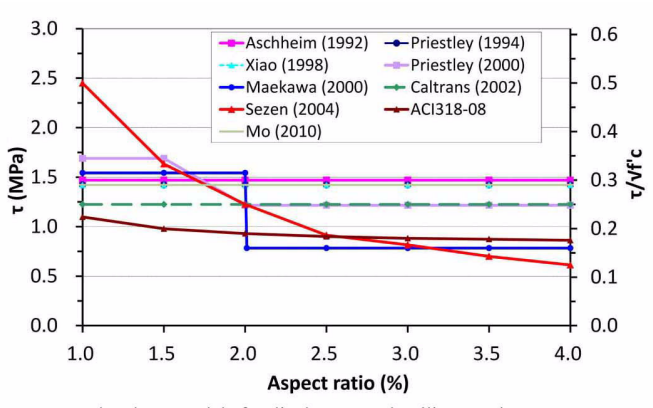

(b) Shear models for displacement ductility equal to 1

Fig. 10 Comparison of shear models in terms of ductility and aspect ratio

others except ACI 318-08. On the other hand, the Caltrans model (2002) expects strength degradation even when the ductility is less than 1 (i.e., before yield displacement) for columns with minimal transverse reinforcement. The models that do not consider the aspect ratio (Ashheim and Moehle 1992, Xiao and Martirossyan 1998, Catrans 2002), presented by dotted lines in the figures, expect faster degradation in concrete shear strength (i.e., rapid line slopes) due to increasing ductility in general. The strength degradation due to increasing ductility is mostly because aggregate interlocking reduces as crack widths become wider (Priestly et al. 1994). Among the models reviewed above, Sezen and Moehle (2004) predicts the highest residual shear strength of concrete at high ductility demand.

Fig. 10(b) illustrates the impact of column aspect ratio for cases of the displacement ductility equal to or less than 1. As mentioned earlier, Ashheim and Moehle (1992), Xiao and Martirossyan 
Table 4 Comparison of experimental and calculated initial shear strengths

\begin{tabular}{|c|c|c|c|c|c|c|c|}
\hline Specimen & H40A 1.5 & $\mathrm{H} 40 \mathrm{~A} 2.0$ & $\mathrm{H} 40 \mathrm{~A} 2.5$ & H40A3.0 & H60A 1.5 & H40A1.5WF1.8 & $\mathrm{H} 40 \mathrm{~A} 2.0 \mathrm{C}$ \\
\hline $\begin{array}{l}\text { Exp. maximum load, } \\
V_{c, \exp }(\mathrm{kN})(1)\end{array}$ & 525 & 445 & 341 & 259 & 337 & 522 & 368 \\
\hline Shear area (2) & $A_{g}$ & $A_{g}$ & $A_{g}$ & $A_{g}$ & $A_{g}$ & $A_{g}$ & $0.8 A_{g}$ \\
\hline $\begin{array}{l}\text { Exp. shear strength, } \\
\tau_{c, \text { exp }}(\mathrm{MPa})(1) /(2)\end{array}$ & 1.63 & 1.38 & 1.06 & 0.80 & 1.57 & 1.62 & 1.43 \\
\hline Shear model & \multicolumn{7}{|c|}{$\begin{array}{c}\left.\text { Ratio of experimental-to-calculated ( } \tau_{c, \text { exp }} \text {-to- } \tau_{c, \text { cal }}\right) \text { shear strength } \\
\text { based on indicated models }\end{array}$} \\
\hline Aschheim \& Moehle (1992) & 1.11 & 0.94 & 0.72 & 0.55 & 1.07 & 1.10 & 0.97 \\
\hline $\begin{array}{l}\text { Xiao \& Martirossvan } \\
(1998)\end{array}$ & 1.15 & 0.97 & 0.74 & 0.57 & 1.11 & 1.14 & 1.00 \\
\hline $\begin{array}{l}\text { Priestley \& Kowalsky } \\
(2000)\end{array}$ & 0.96 & 1.13 & 0.87 & 0.66 & 0.93 & 0.96 & 1.17 \\
\hline Maekawa \& An (2000) & 1.06 & 1.76 & 1.35 & 1.03 & 1.02 & 1.05 & 1.82 \\
\hline Caltrans (2002) & 1.33 & 1.13 & 0.86 & 0.66 & 1.28 & 1.32 & 1.16 \\
\hline Sezen \& Moehle (2004) & 1.07 & 1.21 & 1.16 & 1.05 & 1.03 & 1.06 & 1.25 \\
\hline ACI318-08 (2008) & 1.66 & 1.48 & 1.17 & 0.91 & 1.61 & 1.65 & 1.53 \\
\hline
\end{tabular}

(1998), Catrans Seismic Design Criteria (2002) do not take into account the effect of column aspect ratio. In the revised UCSD model and Maekawa and An (2000), concrete shear strength do not change for columns with the aspect ratio more than 2. ACI 318-08 shows the smallest variation in the concrete contribution due to the aspect ratio, while Sezen and Moehle (2004) proposed the largest change. In general, the models that do not consider the aspect ratio give higher initial shear strengths than the other models for larger aspect ratios than approximately 2 (see Table 4 also).

\section{Evaluation of shear models based on test results}

Figs. 11(a) to 11(e) compare the shear stress vs. ductility response of each specimen with the various shear models reviewed above. Note that the test results and analytical models in this figure were compared in stress term (i.e., MPa units). As discussed earlier, for the specimens tested under monotonic loading, the shear stress, $\tau$, was determined as the lateral load, $V$, divided by the gross section area, $A_{g}$. On the other hand, $0.8 A_{g}$ was used as the effective shear area for H40A2.0C that was subjected to reversed cyclic loading. The two different effective shear areas $\left(A_{g}\right.$ versus $\left.0.8 A_{g}\right)$ were used based on the findings that the shear strength of $\mathrm{H} 40 \mathrm{~A} 2.0 \mathrm{C}$ was roughly $83 \%$ of that of H40A2.0. The use of $0.8 A_{g}$ for $\mathrm{H} 40 \mathrm{~A} 2.0 \mathrm{C}$ was in accordance with most of the existing shear models, which assumed that the confined concrete core would be effective under lateral cyclic loading (Ang et al. 1989). Also, the displacement ductility, $\mu$, of the specimen was taken equal to 1 at the yield displacement $\left(\Delta_{y}\right)$ defined in Fig. 12.

Note that each figure illustrates the entire load-drift response of the specimen with the indicated aspect ratio $(l / h)$, whereas the maximum load (i.e., shear strength) of the specimen is most 


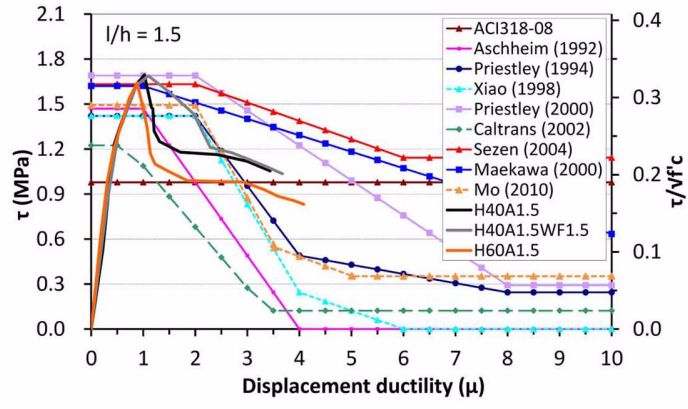

(a) H40A1.5, H40A1.5WF1.8, H60A1.5

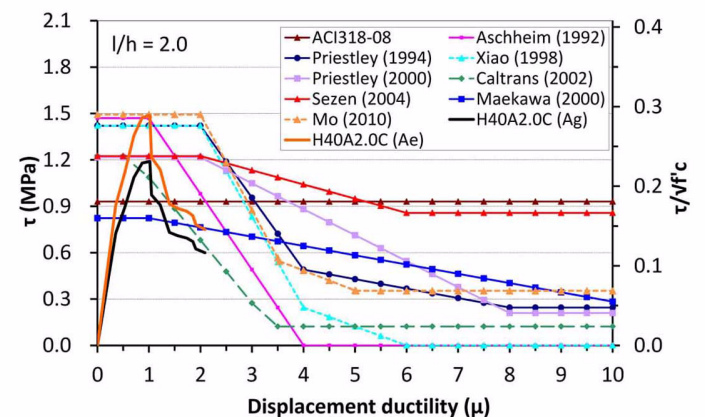

(c) H40A2.0C

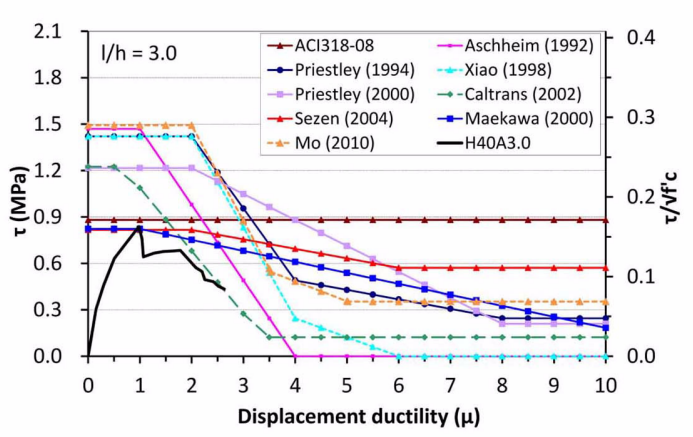

(e) H40A3.0

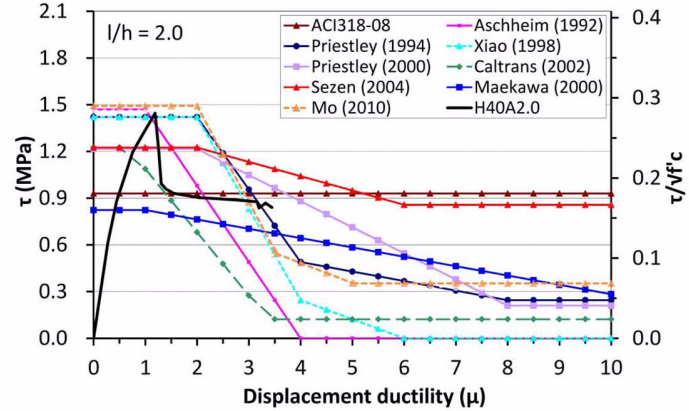

(b) H40A2.0

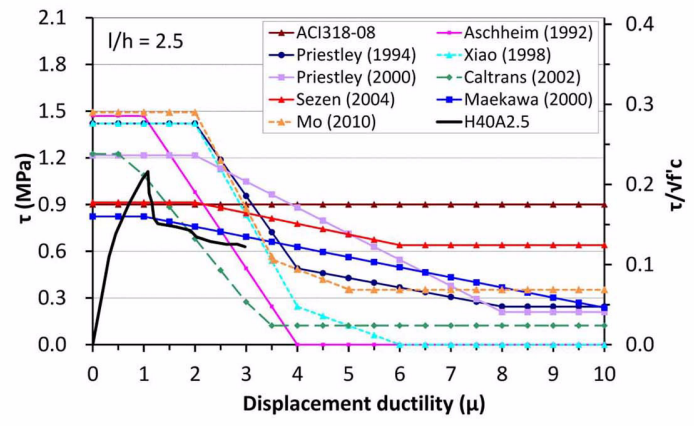

(d) H40A2.5

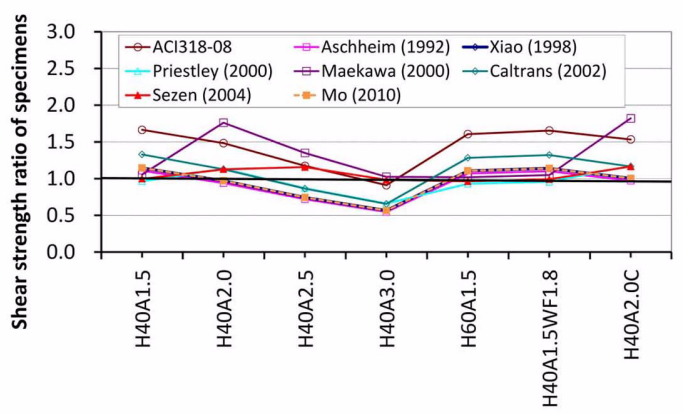

(f) Calculated-to-experimental initial shear stength ratios

Fig. 11 Evaluation of shear models based on test results

meaningful for comparison with the shear models. The shear strength of the specimen was compared with the initial parts of the models, because the specimens failed in shear before reaching their flexural strengths at the displacement ductility slightly larger than 1 . The measured shear strength of each specimen is summarized in Table 4 in both force $\left(V_{c, \text { exp }}\right)$ and stress $\left(\tau_{c, \text { exp }}\right)$ terms, in which the shear strength in stress term $\left(\tau_{c, \text { exp }}\right)$ is equal to the maximum value shown in Figs. 11(a) to $11(\mathrm{e})$. In addition, the ratio of measured-to-calculated initial shear strengths $\left(\tau_{c, \text { exp }}\right.$-to- $\left.\tau_{c, \text { cal }}\right)$ is summarized in Table 4 and also plotted in Fig. 11(f).

For the specimens with the aspect ratio equal to 1.5 and 3.0 shown in Figs. 11(a) and 11(e), Maekawa and An (2000) and Sezen and Moehle (2004) both show good agreement with the measured shear strengths; differences less than $7 \%$ exist between the measured and calculated 


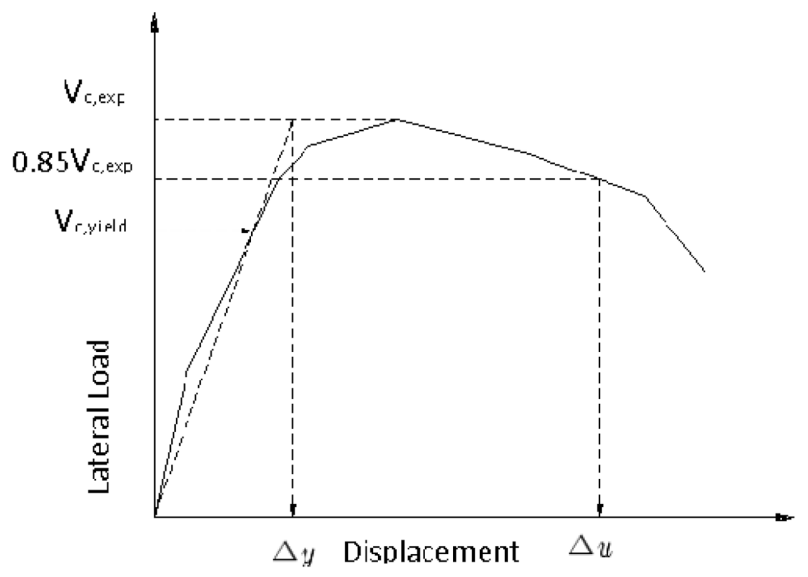

Fig. 12 Definitions for yield displacement $\left(\Delta_{y}\right)$ and displacement ductility $(\mu)$

strengths (see Table 4). Note that Fig. 11(a) includes three specimens, H40A1.5, H40A1.5WF1.8, and H60A1.5, which had the shear strength of $1.63,1.62$, and $1.57 \mathrm{MPa}$, respectively. In particular, only the two aforesaid models give the calculated strengths larger (but very similar) than the measured for H40A3.0. For the other specimens, Sezen and Moehle (2004) shows closer estimation than the others as shown in Fig. 11(f). In general, the ratio of measured-to-calculated shear strengths $\left(\tau_{c, e x p}\right.$-to- $\left.\tau_{c, c a l}\right)$ is smaller in the specimen with the larger aspect ratio (see Fig. 11(f)).

ACI 318-08 gives quite conservative estimates (larger than roughly $150 \%$ of the measured strength) for the specimens with the aspect ratio smaller than 2, while it gives approximately a $10 \%$ smaller estimate for H40A3.0 with the aspect ratio of 3. The ACI 318 method would seem more conservative than shown in Fig. 11 when the measured and calculated shear strengths are compared in force term, because the web area $\left(b_{w} d\right)$ used in ACI 318-08 is smaller than even $0.8 A_{g}$ for the specimens of this study. In this sense, the $10 \%$ smaller estimate for H40A3.0 appears to be in the conservative side. On the other hand, the ACI 318-08 method could be unconservative when high ductility demand (more than about 4 ) is expected, especially for columns with large aspect ratios; in Figs. 11(d) and 11(e), the ACI 318-08 model gives much higher shear strengths than the other shear models.

\section{Proposed model for initial concrete shear strength of hollow columns}

Fig. 13 illustrates an RC column under lateral loading. It may be assumed that an element indicated in the figure is under a uniform stress condition with the shear stress, $\tau$, the normal stress parallel to the column axis, $\sigma_{y}$, and the normal stress perpendicular to the column axis, $\sigma_{x}$. Then, the principal tensile stress, $\sigma_{l}$, may be defined from equilibrium conditions as

$$
\sigma_{1}=\frac{\sigma_{x}+\sigma_{y}}{2}+\sqrt{\left(\frac{\sigma_{x}-\sigma_{y}}{2}\right)^{2}+\tau^{2}}
$$

Here, $\sigma_{x}$ can be assumed zero, which is reasonable in typical hollow columns with no confining 


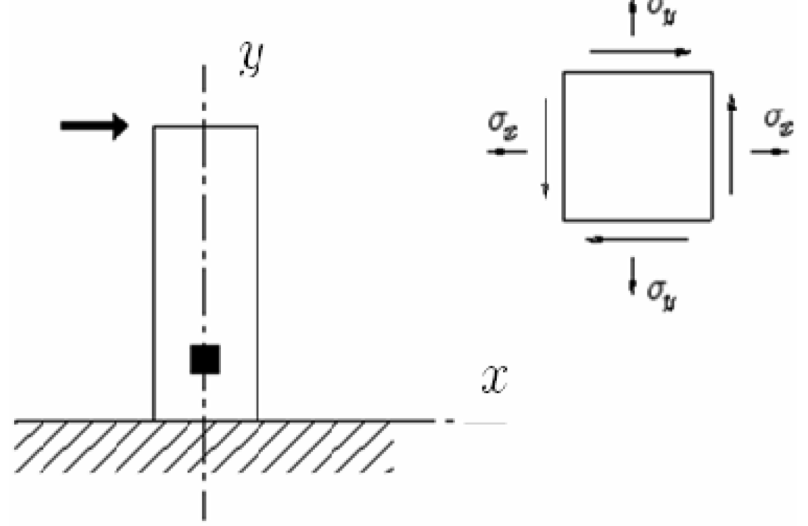

Fig. 13 A column element under normal and shear stresses

lateral reinforcement. Also, $\sigma_{y}$ may be taken as $-P / A_{g}$ (Sezen and Moehle 2004), while the effect of flexural behaviour (i.e., normal stress and bending deformation) on the concrete shear strength is implicitly incorporated by a function of column aspect ratio. Then, inclined shear cracks would occur when the principal tensile stress, $\sigma_{l}$, approaches the nominal tensile strength of concrete, $f_{c t}$. Substituting $\sigma_{x}=0, \sigma_{y}=-P / A_{g}$, and $\sigma_{1}=f_{c t}$ taken equal to $0.5 \sqrt{f_{c}^{\prime}}$ (MPa), the shear stress, $\tau_{c r}$, at the onset of inclined shear cracking can be expressed as

$$
\tau_{c r}=0.5 \sqrt{f_{c}^{\prime}} \sqrt{1+\frac{P}{0.5 \sqrt{f_{c}^{\prime}} A_{g}}}
$$

Note that Eq. (24) does neither reflect the effect of column aspect ratio, nor the effect of increasing ductility. The former is pursued in the following.

Fig. 14 compares the measured shear strength $\left(\tau_{c, \text { exp }}\right)$ with the calculated initial shear strengths $\left(\tau_{c, \text { cal }}\right)$ by the four models that account for the column aspect ratio (Maekawa and An 2000, Kowalsky and Priestley 2000, Sezen and Moehle 2004, ACI 318 2008), for all seven hollow specimens. For the models in Fig. 14, it is considered that the longitudinal steel ratio is the same as that of the specimens (i.e., 0.0018), the axial load is zero, and the displacement ductility is close to one, to place the equal basis as the tests. No conclusion was attempted to be made related to the effect of increasing ductility in this study. As discussed earlier, the Sezen and Moehle's model presents better estimates than the others. Nevertheless, relatively larger differences exist at the aspect ratio of 2.0 and 2.5 between this model and the tests. In the hollow column tests, the initial shear strength reduced in a linear pattern as the column aspect ratio increased, while the strength is proportional to the inverse of the aspect ratio in the Sezen and Moehle's model. For the aspect ratio larger than 3, no apparent reduction in the shear strength was found from previous studies (Leonhardt 1965, Bresler and MacGregor 1967, ASCE-ACI Committee 426 1973). Therefore, it is proposed in this study that the initial shear strength of concrete degrades in a linear pattern (i.e., with a negative slope) up to the aspect ratio of 3 , and does not vary for the aspect ratio larger than 3 .

Ang et al. (1989) found the consistency that, for columns with a certain aspect ratio, shear stress carried by concrete at the maximum load was approximately $30 \%$ higher than shear stress at the 


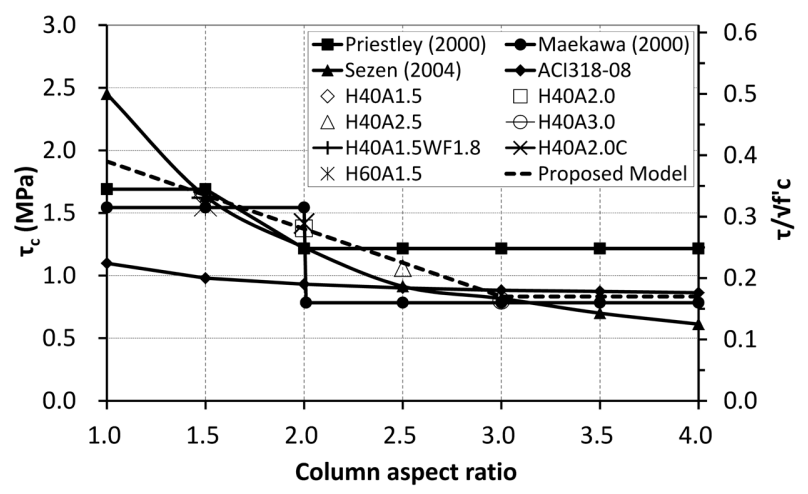

Fig. 14 Effect of aspect ratio on concrete shear strength: experimental shear strengths compared with several models

onset of diagonal cracking. Therefore, the initial concrete shear strength $\left(\tau_{c}\right)$ of an RC hollow column with $0 \leq l / h \leq 3$ may be expressed as a function of $\tau_{c r}$ by

$$
\tau_{c}=\left(c_{1}-c_{2} \frac{l}{h}\right) 0.5 \sqrt{f_{c}^{\prime}} \sqrt{1+\frac{P}{0.5 \sqrt{f_{c}^{\prime}} A_{g}}}
$$

Here, $l / h$ is the column aspect ratio, and $c_{1}$ and $c_{2}$ are unknown constants to be determined based on the test results. In Fig. 14, a linear regression line fitting to the test results of all seven specimens was stated as follows:

$$
\frac{\tau_{c}}{\sqrt{f_{c}^{\prime}}}=0.5\left(1-0.22 \frac{l}{h}\right)
$$

From Eq. (25) and Eq. (26) with substituting $P=0$ in Eq. (25) for the tests of this study, $c_{1}$ and $c_{2}$ are determined to be 1.0 and 0.22 , respectively.

With respect to the shear effective area for RC hollow columns subjected to cyclic lateral loading, $0.8 A_{g}$ was adopted based on the comparison between the shear strengths of H40A2.0 and H40A2.0C, as used in most of the other shear models. Based on the aforesaid findings, it is proposed that the initial shear strength $\left(V_{c}\right)$ of $\mathrm{RC}$ hollow columns owing to concrete only may be assessed by

$$
\begin{aligned}
& \text { Proposed } V_{c}=(\alpha) 0.5 \sqrt{f_{c}^{\prime}} \sqrt{1+\frac{P}{0.5 \sqrt{f_{c}^{\prime}} A_{g}}}\left(0.8 A_{g}\right) \\
& \alpha=1-0.22 \frac{l}{h} \quad \text { for } \frac{l}{h} \leq 3 \\
& \alpha=0.34 \quad \text { for } \frac{l}{h} \geq 3
\end{aligned}
$$


It should be noted, however, that the proposed effect of column aspect ratio $(\alpha)$ is based on the limited number of hollow column tests, due to the lack of available hollow column specimens that failed in premature shear mode; almost all hollow column specimens reported in literature (Yeh et al. 2002, Mo et al. 2003, Mo et al. 2004, Cheng et al. 2005) developed relatively ductile plastic hinging before ultimate shear failure, if any. Also, the effect of longitudinal steel ratio on the concrete shear contribution is not explicitly embodied in the proposed model due to the lack of data. Therefore, more test data should be solicited from the research society of earthquake-resistant design.

\section{Conclusions}

In this study, an experimental program was conducted for seven large-scale reinforced concrete (RC) rectangular hollow columns subjected to monotonic or cyclic lateral loads, to identify concrete contribution to the initial shear strength of such columns. Also, pioneering shear models proposed around the world, all of which were mainly based on tests for columns with solid sections, were reviewed and compared with the test results of this study. Finally, an empirical equation was proposed for the concrete shear contribution in RC hollow columns. The findings and conclusions drawn based on the experimental and analytical results include the following:

1. The specimen with the higher column aspect ratio generally showed the smaller stiffness after the initiation of diagonal cracking, and ultimately reached the smaller maximum load. The reduction in the maximum load was likely in part because the confinement effect of the footing was lesser in columns with higher aspect ratios, and also in part because increased normal stress due to higher bending moment interacted with shear stress against the given tensile capacity of concrete.

2. The two specimens, H40A1.5 and H40A1.5WF1.8, with different web area ratios but with the same gross section area, achieved similar maximum loads (i.e., shear strengths in force term). Also, the two specimens, H40A1.5 and H60A1.5, with different hollow section ratios, had similar maximum loads normalized by their gross section areas (i.e., shear strengths in stress term). Based on these results, it was concluded that the shear strength of an RC hollow column is associated more with the gross section area than the web area.

3. The specimen tested under reversed cyclic loading, H40A2.0C, achieved approximately $83 \%$ of the shear strength of the companion specimen under monotonic loading, H40A2.0. This was mostly because H40A2.0C underwent strength and stiffness degradations due to the crossing of diagonal cracks under reversed cyclic loading.

4. ACI 318-08 gives quite conservative design shear strengths (larger than roughly $150 \%$ of the measured strengths) for the specimens with the aspect ratio smaller than 2 . On the other hand, the ACI 318-08 equation could be unconservative when high ductility demand (more than about 4) is expected, especially for columns with large aspect ratios.

5. The Sezen and Moehle's model presents better shear strength estimates than the other models for the seven hollow specimens of this study. In the hollow column tests, however, the initial shear strength reduced in a linear pattern as the column aspect ratio increased, while the strength is proportional to the inverse of the aspect ratio in the Sezen and Moehle's model.

6. Based on the experimental and analytical results, it was proposed that the initial shear strength of RC hollow columns owing to concrete only may be assessed by Eq. (27). It should be noted, however, that the proposed effect of column aspect ratio is based on the limited number of hollow 
column tests, due to the lack of available hollow column specimens that showed premature shear failure.

\section{Acknowledgements}

This research was supported by Basic Science Research Program through the National Research Foundation of Korea (NRF) funded by the Ministry of Education, Science and Technology (Grant No. 2011-0026780). Also, this work was supported by the 2010 Research Fund of the Ulsan National Institute of Science and Technology (UNIST), Korea. The authors would like to acknowledge continued support from their affiliations.

\section{References}

AASHTO (2002), LRFD Bridge Design Specifications, $2^{\text {nd }}$ Edition, American Association of State Highway and Transportation Officials, Washington, D.C.

ACI Committee 318 (2008), Building Code Requirements for Reinforced Concrete (ACI 318-08) and Commentary (ACI 318R-08), American Concrete Institute, Famington Hills, Michigan.

American Society of Civil Engineers (2007), Seismic Rehabilitation of Existing Buildings, ASCE/SEI 41-06, Reston, VA.

Ang, B.G., Priestley, M.J.N. and Paulay, T. (1989), "Seismic shear strength of circular reinforced concrete columns," ACI Struct. J., 86(1), 45-59.

Applied Technical Council (1981), Seismic Design Guidelines for Highway Bridges, Report No. ATC-6, Berkeley, CA.

Applied Technology Council (1996), Improved Seismic Design Criteria for California Bridges: Provisional Recommendations, Report No. ATC-32, Redwood City, CA.

Applied Technology Council (1996), Seismic Evaluation and Retrofit Concrete Buildings, Report No. ATC-40, Redwood City, CA.

ASCE-ACI Task Committee 426 (1973), "The shear strength of reinforced concrete members," ASCE J. Struct. Div., 99(6), 1091-1187.

Aschheim, A.M. and Moehle, J.P. (1992), "Shear strength and deformability of RC bridge columns subjected to inelastic displacements," Technical Report No. UCB/EERC 92/04, University of California at Berkeley, Berkeley, CA.

Bresler, B. and MacGregor, J.G. (1967), "Review of concrete beams failing in shear," ASCE J. Struct. Div., 93, 343-372.

Caglar, N. (2009), "Neural network based approach for determining the shear strength of circular reinforced concrete columns," Constr. Build. Mater., 23, 3225-3232.

Caltrans (2002), Caltrans Seismic Design Criteria, Version 1.3, California Department of Transportation, Sacramento, CA.

Cheng, C.T., Mo, Y.L. and Yeh, Y.K. (2005), "Evaluation of as-built, retrofitted, and repaired shear-critical hollow bridge columns under earthquake-type loading," ASCE J. Bridge Eng., 10(5), 520-529.

Federal Emergency Management Agency (1997), NEHRP Guidelines for the Seismic Rehabilitation of Buildings, FEMA 273, Washington, D.C.

Federal Emergency Management Agency (2000), Prestandard and Commentary for the Seismic Rehabilitation of Buildings, FEMA 356, Washington, D.C.

Hartsuijker, C. and Welleman, J.W. (2007), Engineering Mechanics, Volume 2: Stresses, Strains, Displacements, Springer, Dordrecht, The Netherlands.

Howser, R., Laskar, A. and Mo, Y.L. (2010), "Seismic interaction of flexural ductility and shear capacity in reinforced concrete columns," Struct. Eng. Mech., 35(5), 593-616. 
Kowalsky, M.J. and Priestley, M.J.N. (2000), "Improved analytical model for shear strength of circular reinforced concrete columns in seismic regions," ACI Struct. J., 97(3), 388-396.

Leonhardt, F. (1965), "Reducing the shear reinforcement in reinforced concrete beams," Mag. Concrete Res., 17(53), 187-198.

Maekawa, K. and An, X. (2000), "Shear failure and ductility of RC columns after yielding of main reinforcement," Eng. Fract. Mech., 65, 335-368.

Mo, Y.L., Wong, D.C. and Maekawa, K. (2003), "Seismic performance of hollow bridge columns," ACI Struct. J., 100(3), 337-348.

Mo, Y.L., Yeh, Y.K. and Hsieh, D.M. (2004), "Seismic retrofit of hollow rectangular bridge columns," $J$. Compos. Constr., 8(1), 60-68.

Mostafaei, H., Vecchio, F.J. and Kabeyasawa, T. (2009), "Deformation capacity of reinforced concrete columns," ACI Struct. J., 106(2), 187-195.

Paulay, T. and Priestley, M.J.N. (1992), Seismic Design of Reinforced Concrete and Masonry Buildings, John Wiley \& Sons, New York, NY.

Priestley, M.J.N., Seible, F. and Calvi, G.M. (1996), Seismic Design and Retrofit of Bridges, John Wiley \& Sons, New York, NY.

Prestley, M.J.N., Verma, R. and Xiao, Y. (1994), "Seismic shear strength of reinforced concrete columns," $J$. Struct. Eng., 120(8), 2310-2329.

Sasani, M. (2007), "Life-safety and near-collapse capacity models for seismic shear behavior of reinforced concrete columns," ACI Struct. J., 104(1), 30-38.

Sezen, H. (2008), "Shear deformation model for reinforced concrete columns," Struct. Eng. Mech., 28(1), 39-52.

Sezen, H. and Moehle, J.P. (2004), "Shear strength model for lightly reinforced concrete columns," J. Struct. Eng., 130(11), 1692-1703.

Stevens, N.J., Uzumeri, S.M. and Collins, M.P. (1991), "Reinforced concrete subjected to reversed cyclic shear experiments and constitutive model," ACI Struct. J., 88(2), 135-146.

Wong, Y.L., Paulay, T. and Priestley, M.J.N. (1993), "Response of circular reinforced concrete columns to multidirectional seismic attack," ACI Struct. J., 90(2), 180-191.

Xiao, Y. and Martirossyan, A. (1998), "Seismic performance of high-strength concrete columns," J. Struct. Eng., 124(3), 241-251.

Yang, K.H., Ashour, A.F. and Song, J.K. (2007), "Shear capacity of reinforced concrete beams using neural network," Int. J. Concrete Struct. Mater., 1(1), 63-73.

Yeh, Y.K., Mo, Y.L. and Yang, C.Y. (2002), "Seismic performance of rectangular hollow bridge column," $J$. Struct. Eng., 128(1), 60-68. 